\title{
When the Damage is Done: Effects of Moral Disengagement on Sustainable Consumption
}

\author{
Sven Kilian \\ University of Kassel \\ Andreas Mann \\ University of Kassel
}

The present research applies moral disengagement theory to explain consumer responses to socioecological attributes of consumption options (e.g., working conditions, climate impact) in the marketplace. We conducted an online experiment demonstrating that participants were likely to engage in self-serving moral reasoning (i.e., moral disengagement) when a presented consumption option with poor socio-ecological performance was perceived as desirable and when a suitable argument (i.e., moral disengagement cue) was available. Furthermore, moral disengagement reduced moral feelings to forgo a consumption option with poor socio-ecological performance and fostered behavioural intentions towards it. These results provide important implications for scholars and public policy alike.

Keywords: moral disengagement, ethical product attributes, consumer social responsibility, sustainable consumption

\section{INTRODUCTION}

Numerous advocates of sustainable development such as marketers of sustainable brands, public policy agents or NGOs are concerned with means to motivate consumers to more sustainable consumption behaviour (i.e., considering socio-ecological implications). A pivotal obstacle to that end is the pervasive and puzzling discrepancy between consumers' stated pro-sustainable attitudes and their actual consumer behaviour (Prothero et al., 2011; Haws et al., 2014; Luchs et al., 2015).

So far, researchers have provided several accounts for the aforementioned attitude-action gap such as lay theories about sustainable products (Gupta and Sen, 2013; Luchs et al., 2010), general world views (Peloza et al., 2013) or stereotypes regarding "ethical" consumer groups (Antonetti and Maklan, 2016). Of particular importance to the effectiveness of marketing techniques as means to encourage sustainable consumer behaviour is an understanding of consumer responses to socio-ecological attributes in the marketplace. Recent research demonstrates that consumers are likely to engage in cognitive defence mechanisms regarding information about socio-ecological attributes of potential consumption options which in turn impede their influence on consumption decisions, which could otherwise has been exerted through an activation of the consumers' conscience. For instance, consumers tend to willfully ignore (Ehrich and Irwin, 2005) and are disproportionately more likely to forget about socio-ecological product attributes than about "traditional" attributes such as quality or price (Reczek et al., 2018). By these 
defence mechanisms, consumers avoid negative and potentially conflicting emotions in the presence of ethical issues (Reczek et al., 2018). Therefore, to ensure that information about socio-ecological performance of potential consumption options can reach consumers' conscience, it is advised to place the relevant information near to the actual evaluation context (e.g., point of sale) and in a way they cannot be ignored (Ehrich and Irwin, 2005).

However, the current research proposes that this is still not enough to ensure the activation of the consumers' conscience in regard of unsustainable consumption options. We suggest that even when having full information about the detrimental socio-ecological aspects at hand, another cognitive defence mechanism comes to play, i.e., moral disengagement (Bandura et al., 1996). "Moral disengagement" refers to a set of self-favouring reasoning mechanisms which allow individuals to justify actions that deviate from internal moral standards (Bandura, 1999). These mechanisms have been studied in several behavioural areas and were frequently able to explain why people deviate from commonly held moral standards across different domains, such as in criminology or military psychology (DeLisi et al., 2014; Martin et al., 2014; Aquino et al., 2007). Yet, research on sustainable consumption paid very little attention to these mechanisms thus far (Moore, 2015), despite the similarity of conditions in the context of unsustainable behaviour with a socially deviant behaviour and a (potential) disregard of one's own moral standards.

Therefore, the current research's main objective is to probe consumers' tendencies to engage in moral disengagement mechanisms in face of consumption options with poor socio-ecological performance and to examine how these mechanisms relate to the activation of consumers' conscience and subsequent consumption decisions. Applying moral disengagement theory to the domain of sustainable consumption, we improve the body of knowledge about consumer responses to socio-ecological attributes of consumption options. This knowledge can guide advocates of sustainable development to improve marketing activities aiming to facilitate sustainable consumption and to curtail the pervasive and puzzling attitude-action-gap.

\section{THEORETICAL FRAMEWORK}

Theories of moral conduct argue, most people have a general desire to be righteous and care for the outcomes of creatures apart from themselves (Kohlberg, 1984; Bandura, 1986; Haidt, 2007). Morality enters consumer behaviour partly through information about socio-ecological attributes of potential consumption options (Reczek et al., 2018). Social cognitive theory suggests that a process of internal selfmonitoring reflects perceived moral implications of behaviours against internalized moral standards (e.g., purchasing a product produced with child labour), which results in a moral judgment (i.e., whether the behaviour is concluded to be right or wrong) (Bandura et al., 1996). The moral judgment does not necessarily involve deliberate thinking and is often the result of intuitive processes (Haidt, 2001). However, when a behaviour is judged as morally wrong, activation of self-sanctioning processes induces feelings of moral obligation along with moral emotions that steer motivation to refrain from the apparent behaviour (e.g., not buying the product produced with child labour) (Onwezen et al., 2013).

Moral disengagement theory argues, this process of "conscience activation" can be selectively offset by motivated reasoning mechanisms interfering with the moral judgment (Bandura et al., 1996). This allows individuals to engage in behaviours that would otherwise activate internal self-sanctioning processes (Bandura, 1999). To that end, moral disengagement theory discusses eight mechanisms that comprise re-construing the behaviour as actually moral, obscuring causal agency, disregarding or misrepresenting injurious consequences, and blaming or devaluating the victims (Bandura et al., 1996). While moral disengagement was originally discussed as a process, within research it was mostly measured as a stable personal trait (Moore, 2015). However, recent studies established empirical evidence that moral disengagement mechanisms can be motivated to justify self-interest (Shu et al., 2011; Gino and Galinsky, 2012; Paharia et al., 2013).

In the context of sustainable consumption, people frequently have to ponder self-interest against social benefits (Campbell and Winterich, 2018; Steg, 2015). For instance, products with high socio- 
ecological standards are often more expensive than products with lower socio-ecological standards (e.g., Steg, 2015). Such dilemma situations are often conceptualized as conflicts between a "want self" and a "should self" (Bazerman et al., 1998; Thaler and Shefrin, 1981). This distinction is attributed to different cognitive systems for self-interest and concern for others (Moore and Loewenstein, 2004). Research points out, when these selves conflict, individuals are likely to engage in coping strategies to avoid corresponding distressful emotions (Luce, 1998; Baumeister, 2002). In the current research we propose that such tensions can also motivate moral disengagement. We suggest, when consumers encounter consumption options that are appealing to self-interest (i.e., when they are desirable), but opposing to internal moral standards because of poor socio-ecological performance, they are likely to engage in motivated moral disengagement processes to allow for pursuit of personal desire with clear conscience.

We suggest that consumers equipped with a proper argument will increasingly bear on it to morally disengage when want/should conflicts arise (e.g., when perceived desirability increases). We expect no such pattern when want/should conflicts are not apparent. Hence, we propose the following hypothesis:

H1: When contemplating a consumption option with poor socio-ecological performance and an argument for moral disengagement (MD Cue) is available, consumers will exhibit moral disengagement mechanisms (i.e. endorse self-serving reasoning) with increasing perceived desirability of the consumption option.

We argue, the expected pattern of moral disengagement is motivated by a desire to reduce conflicting moral feelings in favour of self-interest. Therefore, it is proposed that:

H2: Higher levels of moral disengagement induce lower levels of moral feelings to forgo a consumption option with poor socio-ecological performance (i.e., less activation of consumers' conscience).

We further propose that these lower levels of moral feelings will result in more favourable intentions towards the consumption option and in decreased willingness to pay for higher socio-ecological performance (e.g., $\mathrm{CO}_{2}$ neutrality). Therefore, we propose that the influence of moral disengagement mechanisms on behavioural intentions and willingness to pay is mediated by reduced moral feelings regarding the unsustainable consumption option (see Figure 1). Hence, we propose the following hypotheses:

H3a: Motivated moral disengagement will increase the intention to purchase a consumption option with poor socio-ecological performance via reduced moral feelings regarding the consumption option.

H3b: Motivated moral disengagement will increase the word-of-mouth intention regarding a consumption option with poor socio-ecological performance via reduced moral feelings regarding the consumption option.

H3c: Motivated moral disengagement will decrease the willingness to pay for better socio-ecological performance via reduced moral feelings regarding the consumption option. 


\section{FIGURE 1}

\section{RESEARCH MODEL}

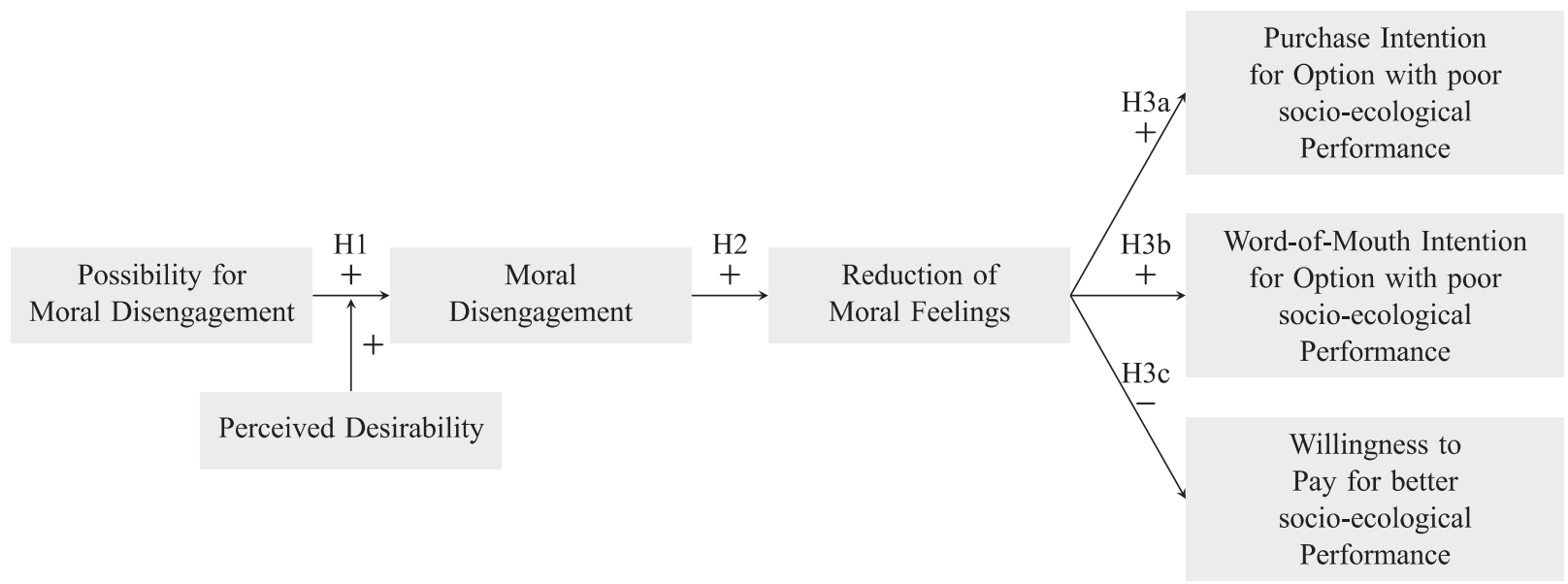

\section{METHOD}

To test the proposed hypotheses, we picked up a discourse in normative consumer ethics, in the context of which it is sometimes argued that just by acquiring goods with detrimental socio-ecological impact due to product production, the consumers cannot be held accountable for that, because when consumers enter the marketplace, the damage is already done (Kagan, 2011; Norcross, 2004; Schmidt, 2014). In an online experiment, we utilize the tendency of participants to support this point of view as an indicator for moral disengagement mechanisms (i.e., reduced perceived self-accountability for $\mathrm{CO}_{2}$ impact). Realize, a desirability-dependent advocacy for this reasoning from a consumer perspective would be akin to the moral disengagement mechanism of disregarding or distorting the consequences of one's own actions (Bandura et al., 1996).

The online experiment was conducted in spring 2019 at a large University in Germany. 306 participants $\left(M_{\text {age }}=25.35 ; 45.8 \%\right.$ female $)$ were recruited in exchange for a five euro compensation from a local subject pool. During the initial registration process, participants already responded to a measure of green consumption values by Haws et al. (2014), which was enclosed within other personality traits. To prevent priming effects from responding to the GREEN scale, only after a time period of forty-eight hours (not known to the participants), the invitation link for the study was sent by email.

Participants clicked on the link in the invitation email and started the study. After reading a short introduction, a shopping good (i.e., camping chair) was presented in a typical "Amazon Way" (see Appendix A). To manipulate perceptions of socio-ecological performance, we used a fictional rating (for a similar approach, see Luchs et al., 2010) stating a high carbon footprint in the production of the product. At first, participants were asked to judge different dimensions of product quality and desirability. These measures also included a manipulation check for the perceived socio-ecological performance of the product, which were measured on 7-point scales with the items "environmentally harmful" vs. "environmentally friendly", "climate-damaging" vs. "climate-friendly" and "ecologically short-sighted" vs. "ecologically sustainable" (Cronbach's $\alpha=.725$ ). The averaged sum score indicated that our sustainability manipulation was successful and participants perceived the product as of poor socioecological performance (t-test vs. scale midpoint of four; $t(305)=-31.92, M=2.15, p<.001$ ).

In the following, participants were provided with different information regarding the production status of the product to control the possibility for moral disengagement. We randomly assigned participants to one of three treatment conditions. In the first condition (MD Cue), participants received information that the product is already produced by the time they will order it. This would generally allow for the moral disengagement mechanism proposed above (e.g., "I cannot be held accountable for the 
damage since the damage is already done"). In the second condition (Counter MD Cue) participants read that the product they investigate will be only produced after they ordered it. This would generally permit the proposed moral disengagement mechanism. In the third condition (No Cue) participants received no additional information about the production status by the time of product investigation, which provides a control group. We further refer to this variable simply as "production status".

Next, to capture potential tendencies for moral disengagement mechanisms, participants were asked to judge how much they perceive themselves as personally accountable for the $\mathrm{CO}_{2}$ impact the production has caused if they purchase the product (two items with Cronbach's $\alpha=.881$ ) (see Appendix B). Then, they responded to a scale measuring their moral feelings to forgo purchasing the product on five items (Cronbach's $\alpha=.917$ ). Finally, they indicated their purchase intention on two items (Cronbach's $\alpha=$ .874 ), their word-of-mouth intention on three items (Cronbach's $\alpha=.928$ ) and their willingness to pay for $\mathrm{CO}_{2}$ neutrality on one item (open entry in Euro).

Within collecting responses to these items, we also addressed the possibility that participants of our study might be motivated to present themselves in a positive light because ethics are involved (Kruger and Gilovich, 2004).We suspected tendencies of social desirability to overwrite potential effects of moral disengagement by merely pushing responses towards upper scale levels regardless of potential real-world effects in the other direction. Therefore, only half of the respondents were to rate the measures of selfaccountability, moral feelings and behavioural intentions on behalf of themselves (direct-question condition). The other half was asked to rate these measures on behalf of a typical German consumer (indirect-question condition). This projective technique is able to reduce socially desirable responding (Fisher, 1993; Luchs et al., 2010). Thus, the study employed a $3 \times 2$ between subject design. Lastly, participants responded to other manipulation checks and to demographic measures all on behalf of themselves.

\section{RESULTS}

\section{Effects of Production Status and Perceived Desirability on Self-Accountability Judgments for $\mathrm{CO}_{2}$ Impact}

First, we conducted a series of ANOVAs which confirmed that there were no systematic differences in the levels of green consumption values $(F(300,5)=1.19, p=.32)$, ratings on socio-ecological product performance $(F(300,5)=.90, p=.48)$ and product desirability $(F(300,5)=1.25, p=.29)$ across the six experimental groups, which could have otherwise confounded the results. Next, we utilized SPSS PROCESS v3.4 (model 3, Hayes, 2018) to test our first hypothesis. We entered perceived selfaccountability for $\mathrm{CO}_{2}$ impact as dependent variable $(Y)$ and production status as independent variable $(X)$. Perceived product desirability was entered as first moderator $(M)$ and question type as second moderator $(W)$ (see Appendix C, PROCESS Model 3). The overall model was significant $(F(300,5)=$ $20.35, p<.001)$. Further spotlight analysis reveals that in the direct-question condition no systematic interaction between production status and perceived desirability on judgments of self-accountability for $\mathrm{CO}_{2}$ impact $(F(294,2)=.35, p>.70)$ occurred. Moreover, as suspected in all three production status groups in the direct-question condition, participants judged their perceived self-accountability for $\mathrm{CO}_{2}$ impact significantly above the midpoint of four (MD Cue Group: $t(56)=10.44, M=5.45, \mathrm{p}$ $<.001$; Counter MD Cue Group: $t(50)=12.11, M=5.76, p<.001$; No Cue Group: $t(47)=9.45, M=$ $5.34, p<.001)$. This indicates the anticipated tendencies of responses towards the upper scale extremes when participants were being asked directly.

However, turning spotlight analysis to the indirect-question condition, we found the expected interaction effect between production status and perceived desirability on judged self-accountability for $\mathrm{CO}_{2}$ impact $(F(294,2)=5.28, p<.01)$ (see Figure 2$)$. 


\section{FIGURE 2 \\ INTERACTION OF PRODUCTION STATUS AND PRODUCT DESIRABILITY ON SELF- ACCOUNTABILITY JUDGMENTS FOR $\mathrm{CO}_{2}$ IMPACT}

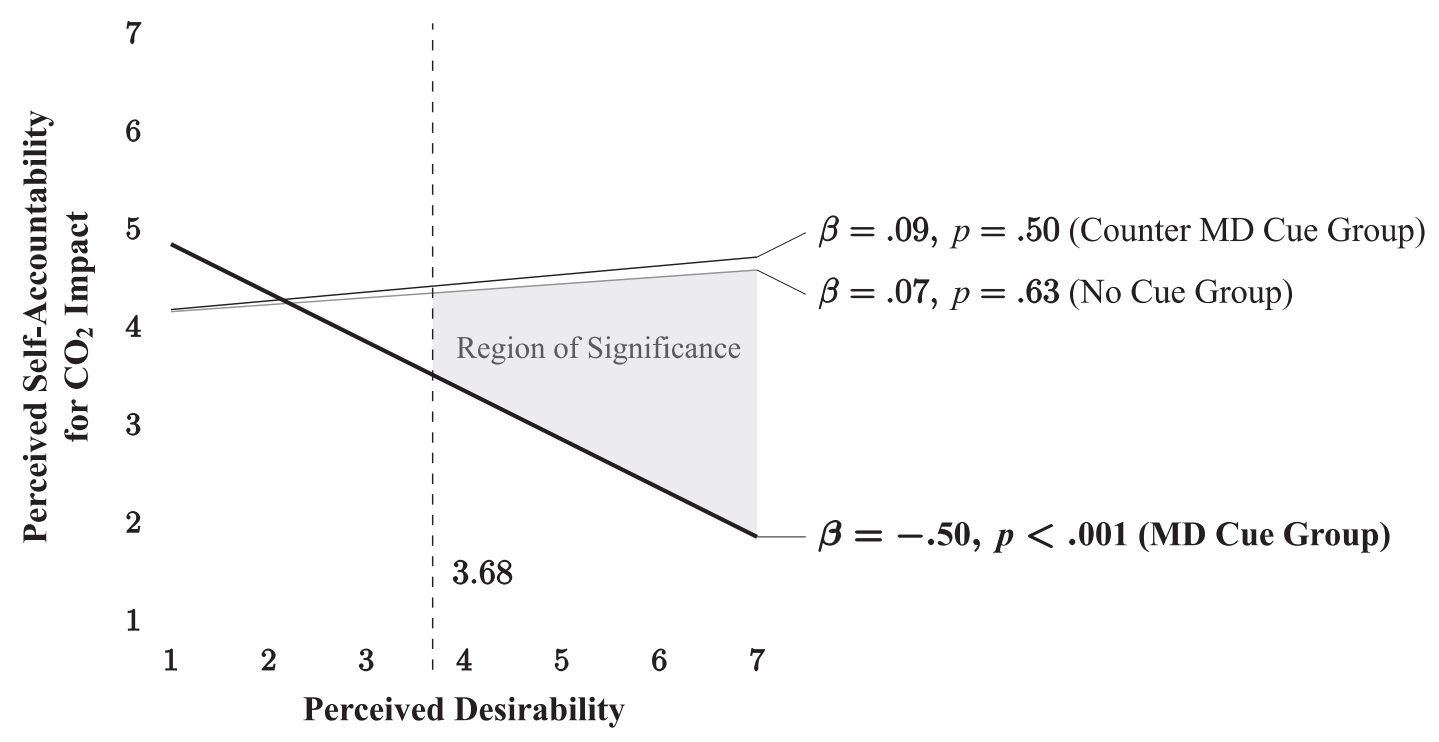

As expected, further analysis reveals judgments of self-accountability were only affected by perceived product desirability in the MD Cue condition (i.e., when the possibility for moral disengagement was apparent) $(\beta=-.50, p<.001)$. In the Counter MD Cue condition $(\beta=.07, p>.60)$ and No Cue condition $(\beta=.09, p>.50)$, where no suitable argument was apparent, judgments of selfaccountability for $\mathrm{CO}_{2}$ impact were unaffected by perceived product desirability. We further examined the interaction with a Johnson-Neyman floodlight analysis. This approach identifies at which level(s) group differences on the dependent variable reach significance, based on the ratio of the conditional effect to its standard error (Hayes, 2018). The analysis indicates a boundary of significance at product desirability rating of 3.68. That means, no significant differences in self-accountability judgments for $\mathrm{CO}_{2}$ impact across all groups of production status occurred when the product desirability was judged below this point. However, above this point (i.e., when the product was judged as desirable) participants with the possibility to morally disengage (MD Cue Group) lowered their judgments of perceived selfaccountability for $\mathrm{CO}_{2}$ impact in accordance with perceived product desirability. This indicates the expected pattern akin to the moral disengagement mechanism of disregarding or distorting the consequences of one's own actions in favour of self-interest. Therefore, hypothesis 1 is supported.

\section{Downstream Consequences of Moral Disengagement on Moral Feelings and Behavioural Intentions}

Next, we examined whether the pattern of desirability-dependent moral disengagement relates to consumers' moral feelings to forgo the product and to subsequent behavioural intentions. To test our hypotheses, we conducted a moderated mediation analysis using SPSS PROCESS v3.4 (Hayes, 2018) with customized models for each of the three behavioural intentions (i.e., purchase intention, word-ofmouth intention, willingness to pay for $\mathrm{CO}_{2}$ neutrality) with bias corrected bootstrapping $(\mathrm{N}=5000)$ to generate $95 \%$ confidence intervals (CIs). Production status was included as independent variable $(X)$, selfaccountability for $\mathrm{CO}_{2}$ impact (M1) and moral feelings to forgo the product (M2) as serial mediators and the respective consumer intention as dependent variable $(Y)$. Again, we entered perceived desirability $(W)$ as the moderator of the relationship between production status and self-accountability for $\mathrm{CO}_{2}$ impact, as well as questioning type $(Z)$ as the moderator of that moderation (see Appendix C, PROCESS Custom Model). The overall model was significant $(F(294,11)=10.95, p<.001)$. Further spotlight analysis 
revealed no significant moderated mediation for all three behavioural intentions in the direct-question condition (i.e., all confidence intervals included zero). However, further examination of the indirectquestion condition revealed, the desirability-dependent judgments of self-accountability for $\mathrm{CO}_{2}$ product impact in the MD Cue condition (i.e., allowing for moral disengagement) were indeed related to significantly lower levels of moral feelings compared to both the Counter MD Cue condition (index = $-.292 ; 95 \% \mathrm{CI} ;-.589$ to -.023 ) and the No Cue condition (index $=-.302 ; 95 \% \mathrm{CI} ;-.531$ to -.079 ), supporting hypothesis 2. Furthermore, the moderated mediation pathways for all three behavioural intentions in the indirect-question condition were significant (see Table 1). The moral disengagement process increased intentions to purchase the product as well as the intentions for word-of-mouth and decreased the willingness to pay for $\mathrm{CO}_{2}$ neutrality. Therefore, these data support hypotheses $3 \mathrm{a}-3 \mathrm{c}$.

\section{TABLE 1 \\ MODERATED MEDIATION OF PRODUCTION STATUS AND PERCEIVED DESIRABILITY ON BEHAVIOURAL INTENTIONS (ONLY INDIRECT-QUESTION CONDITION)}

\begin{tabular}{|c|c|c|}
\hline Path & $\begin{array}{l}\text { Index of Moderated Mediation } \\
\text { (MD Cue vs. Counter MD } \\
\text { Cue) with } \\
95 \%-\text { CI }\end{array}$ & $\begin{array}{l}\text { Index of Moderated } \\
\text { Mediation (MD Cue vs. } \\
\text { No Cue) with 95\%-CI }\end{array}$ \\
\hline $\mathrm{PS} \times \mathrm{PD} \rightarrow \mathrm{pAC} \rightarrow \mathrm{MF} \rightarrow \mathrm{PI}$ & {$[.010, .315]$} & {$[.042, .294]$} \\
\hline $\mathrm{PS} \times \mathrm{PD} \rightarrow \mathrm{pAC} \rightarrow \mathrm{MF} \rightarrow \mathrm{WoM}$ & {$[.013, .299]$} & {$[.040, .290]$} \\
\hline $\mathrm{PS} \times \mathrm{PD} \rightarrow \mathrm{pAC} \rightarrow \mathrm{MF} \rightarrow \mathrm{WtP}$ & {$[-1.377,-0.040]$} & {$[-1.084,-.1250]$} \\
\hline
\end{tabular}

PS: Production Status; PD: Product Desirability; pAC: perceived Self-Accountability for $\mathrm{CO}_{2}$ Impact; MF: Moral Feelings; PI: Purchase Intention; WOM: Word-of-Mouth Intention; WtP: Willingness to pay for $\mathrm{CO}_{2}$ Neutrality

\section{DISCUSSION AND CONCLUSIONS}

Our results show that participants of the current study were indeed likely to engage in moral disengagement processes when the product was perceived as desirable and a possibility for moral disengagement (i.e., a suitable argument) was apparent. Motivated moral disengagement induced lower moral feelings to forgo a product with poor socio-ecological performance and in turn facilitated favourable purchase intentions, word-of-mouth intentions, as well as hampered willingness to pay for better socio-ecological performance (i.e., $\mathrm{CO}_{2}$ neutrality).

These findings have implications in a variety of ways. First, within the literature of sustainable consumption they contribute to the broader discussion on why there is a gap between attitudes and actual behaviours of consumers regarding sustainable behaviour like purchasing products with better socioecological performance (Carrington et al., 2014). Our results suggest that, even though internally held standards and concurring moral feelings could steer consumers' motivation away from consumption options with poor socio-ecological performance, they might still be likely to deactivate these moral feelings by engaging in adaptive reasoning processes to allow pursuit of self-interest over the greater good. These mechanisms generate consumer actions (e.g. shopping sweatshop-produced clothes) that can be opposed to elsewhere differently stated attitudes regarding sustainable purchasing (e.g., in market polls), hence generating an attitude-action gap.

Second, marketing academics dealing with the question of how to motivate sustainable consumption continuously call for research that addresses perceptions and attitudes of consumers regarding their own responsibility for sustainability (Luchs et al., 2015; McGregor, 2017). Our current research highlights that consumers' responsibility perceptions and feelings for sustainability are no stable constructs over time. Adaptive and context-dependent moral disengagement mechanisms are situationally determining the 
actual appearance of consumers' conscience in the marketplace. These must be taken into account to fully understand the practice of consumer (ir-) responsibility in the context of sustainable consumption.

Third, our findings provide insights to the question of how to promote sustainable consumption in the marketplace. Complementing activities with specially tailored communication strategies and message frames that mitigate the potential for moral disengagement might be crucial to the effectiveness of information-based strategies such as product labels or public campaigns. For instance, marketing initiatives (perhaps endorsed by popular celebrities) that actively refute particular arguments for particular issues (e.g., fair trade, organic products) most suitable and common for moral disengagement mechanisms, might just be one of many imaginable approaches. After all, the most persuasive and visible campaigns are worthless if consumers will finally overwrite their moral feelings with disputable reasons.

However, there are limitations that should be mentioned. First, our study was conducted for one particular product under laboratory conditions that might provide results differing from real market fields and from other product contexts and might induce unobserved demanding effects. Second, we relied on a convenience sample containing younger and more educated participants than the general public, which might concur with a particular sensitivity for sustainability related issues. Third, our behavioural items were only measures for intentions which often overstate actual sustainable behaviour. Although, the overall framing of the intention in the context of the current study was related to forgoing a rather unsustainable product, which implies even higher real field effects of moral disengagement on consumption decisions if the intentions measured here overstate real marketplace behaviour. Fourth, we only examined subjects who live in Germany and it may well be that in countries with a different cultural background, the moral principles underlying sustainable consumption are different and thus effects of moral disengagement are stronger or weaker.

Hence, the current study provides a promising glimpse on the role of moral disengagement mechanisms in the domain of sustainable consumption and gives rise to a plethora of questions for future research. For instance, what is the role of the other moral disengagement mechanisms, what other predictors might be relevant for the emergence of moral disengagement and how to mitigate it? Thus, it is our believe that considering moral disengagement theory to facilitate sustainable development will be a worthwhile avenue for future research and practical developments in marketing.

\section{REFERENCES}

Antonetti, P., \& Maklan, S. (2016). Hippies, greenies, and tree huggers: How the "warmth" stereotype hinders the adoption of responsible brands. Psychology \& Marketing, 33(10), 796-813.

Aquino, K., Reed, A., Thau, S., \& Freeman, D. (2007). A grotesque and dark beauty: How moral identity and mechanisms of moral disengagement influence cognitive and emotional reactions to war. Journal of Experimental Social Psychology, 43(3), 385-392.

Bandura, A. (1986). Social Foundations of Thought and Action: A Social Cognitive Theory. Prentice Hall, Englewood Cliffs, NJ.

Bandura, A. (1999). Moral disengagement in the perpetration of inhumanities. Personality and Social Psychology Review, 3(3), 193-209.

Bandura, A., Barbaranelli, C., Caprara, G. V., \& Pastorelli, C. (1996). Mechanisms of moral disengagement in the exercise of moral agency. Journal of Personality and Social Psychology, 71(2), 364-374.

Baumeister, R. F. (2002). Yielding to temptation: Self-control failure, impulsive purchasing, and consumer behavior. Journal of Consumer Research, 28(4), 670-676.

Bazerman, M. H., Tenbrunsel, A. E., \& Wade-Benzoni, K. (1998). Negotiating with yourself and losing: Making decisions with competing internal preferences. Academy of Management Review, 23(2), 225-241.

Campbell, M. C., \& Winterich, K. P. (2018). A framework for the consumer psychology of morality in the marketplace. Journal of Consumer Psychology, 28(2), 167-179. 
Carrington, M. J., Neville, B. A., \& Whitwell, G. J. (2014). Lost in translation: Exploring the ethical consumer intention-behavior gap. Journal of Business Research, 67(1), 2759-2767.

DeLisi, M., Peters, D. J., Dansby, T., Vaughn, M. G., Shook, J. J., \& Hochstetler, A. (2014). Dynamics of psychopathy and moral disengagement in the etiology of crime. Youth Violence and Juvenile Justice, 12(4), 295-314.

Ehrich, K. R., \& Irwin, J. R. (2005). Willful ignorance in the request for product attribute information. Journal of Marketing Research, 42(3), 266-277.

Fisher, R. J. (1993). Social desirability bias and the validity of indirect questioning. Journal of Consumer Research, 20(2), 303-315.

Gino, F., \& Galinsky, A. D. (2012). Vicarious dishonesty: When psychological closeness creates distance from one's moral compass. Organizational Behavior and Human Decision Processes, 119(1), 15-26.

Gupta, R., \& Sen, S. (2013). The effect of evolving resource synergy beliefs on the intentions-behavior discrepancy in ethical consumption. Journal of Consumer Psychology, 23(1), 114-121.

Haidt, J. (2001). The emotional dog and its rational tail: a social intuitionist approach to moral judgment. Psychological review, 108(4), 814-834.

Haidt, J. (2007). The new synthesis in moral psychology. Science (New York, N.Y.), 316(5827), 998-1002.

Harland, P., Staats, H., \& Wilke, H. A. M. (2007). Situational and personality factors as direct or personal norm mediated predictors of pro-environmental behavior: Questions derived from norm-activation theory. Basic and Applied Social Psychology, 29(4), 323-334.

Haws, K. L., Winterich, K. P., \& Naylor, R. W. (2014). Seeing the world through green-tinted glasses: Green consumption values and responses to environmentally friendly products. Journal of Consumer Psychology, 24(3), 336-354.

Hayes, A. F. (2018). Introduction to mediation, moderation, and conditional process analysis: A regression-based approach. Methodology in the social sciences. The Guilford Press, New York and London, second edition.

Kagan, S. (2011). Do i make a difference? Philosophy \& Public Affairs, 39(2), 105-141.

Kohlberg, L. (1984). The psychology of moral development: The nature and validity of moral stages, volume / Lawrence Kohlberg; Vol. 2 of Essays on Moral Development. Harper \& Row, San Francisco.

Kruger, J., \& Gilovich, T. (2004). Actions, intentions, and self-assessment: The road to selfenhancement is paved with good intentions. Personality and Social Psychology Bulletin, 30(3), 328-339.

Lindenmeier, J., Schleer, C., \& Pricl, D. (2012). Consumer outrage: Emotional reactions to unethical corporate behavior. Journal of Business Research, 65(9), 1364-1373.

Luce, M. F. (1998). Choosing to avoid: Coping with negatively emotion-laden consumer decisions. Journal of Consumer Research, 24(4), 409-433.

Luchs, M. G., Naylor, R. W., Irwin, J. R., \& Raghunathan, R. (2010). The sustainability liability: Potential negative effects of ethicality on product preference. Journal of Marketing, 74(5), 18-31.

Luchs, M. G., Phipps, M., \& Hill, T. (2015). Exploring consumer responsibility for sustainable consumption. Journal of Marketing Management, 31(13-14), 1449-1471.

Martin, S. R., Kish-Gephart, J. J., \& Detert, J. R. (2014). Blind forces: Ethical infrastructures and moral disengagement in organizations. Organizational Psychology Review, 4(4), 295-325.

McGregor, S. L. T. (2017). Consumer perceptions of responsibility. In Emilien, G., Weitkunat, R., and Lüdicke, F., editors, Consumer perception of product risks and benefits, (vol. 23, pp. 567-596). Springer, Cham, Switzerland.

Moore, C. (2015). Moral disengagement. Current Opinion in Psychology, 6, 199-204.

Moore, D. A., \& Loewenstein, G. (2004). Self-interest, automaticity, and the psychology of conflict of interest. Social Justice Research, 17(2), 189-202.

Norcross, A. (2004). Puppies, pigs, and people: Eating meat and marginal cases. Philosophical Perspectives, 18(1), 229-245. 
Onwezen, M. C., Antonides, G., \& Bartels, J. (2013). The norm activation model: An exploration of the functions of anticipated pride and guilt in pro-environmental behaviour. Journal of Economic Psychology, 39, 141-153.

Paharia, N., Vohs, K. D., \& Deshpandé, R. (2013). Sweatshop labor is wrong unless the shoes are cute: Cognition can both help and hurt moral motivated reasoning. Organizational Behavior and Human Decision Processes, 121(1), 81-88.

Peloza, J., White, K., \& Shang, J. (2013). Good and guilt-free: The role of self-accountability in influencing preferences for products with ethical attributes. Journal of Marketing, 77(1), 104119.

Perugini, M., \& Bagozzi, R. P. (2001). The role of desires and anticipated emotions in goal-directed behaviours: Broadening and deepening the theory of planned behaviour. British Journal of Social Psychology, 40(1), 79-98.

Prothero, A., Dobscha, S., Freund, J., Kilbourne, W. E., Luchs, M. G., Ozanne, L. K., \& Thøgersen, J. (2011). Sustainable consumption: Opportunities for consumer research and public policy. Journal of Public Policy \& Marketing, 30(1), 31-38.

Reczek, R. W., Irwin, J. R., Zane, D. M., \& Ehrich, K. R. (2018). That's not how i remember it: Willfully ignorant memory for ethical product attribute information. Journal of Consumer Research, 45(1), $185-207$.

Schmidt, I. (2014). Consumer Social Responsibility. Dissertation, Universität Witten, Herdecke.

Shu, L. L., Gino, F., \& Bazerman, M. H. (2011). Dishonest deed, clear conscience: when cheating leads to moral disengagement and motivated forgetting. Personality and Social Psychology Bulletin, 37(3), 330-349.

Steg, L. (2015). Environmental psychology and sustainable consumption. In Reisch, L. and Thøgersen, J., editors, Handbook of Research on Sustainable Consumption, pages 70-83. Edward Elgar Publishing.

Steg, L., \& de Groot, J. (2010). Explaining prosocial intentions: Testing causal relationships in the norm activation model. British Journal of Social Psychology, 49(Pt 4), 725-743.

Thaler, R. H., \& Shefrin, H. M. (1981). An economic theory of self-control. Journal of Political Economy, 89(2), 392-406. 


\section{APPENDICES}

\section{A. Experimental Stimuli}
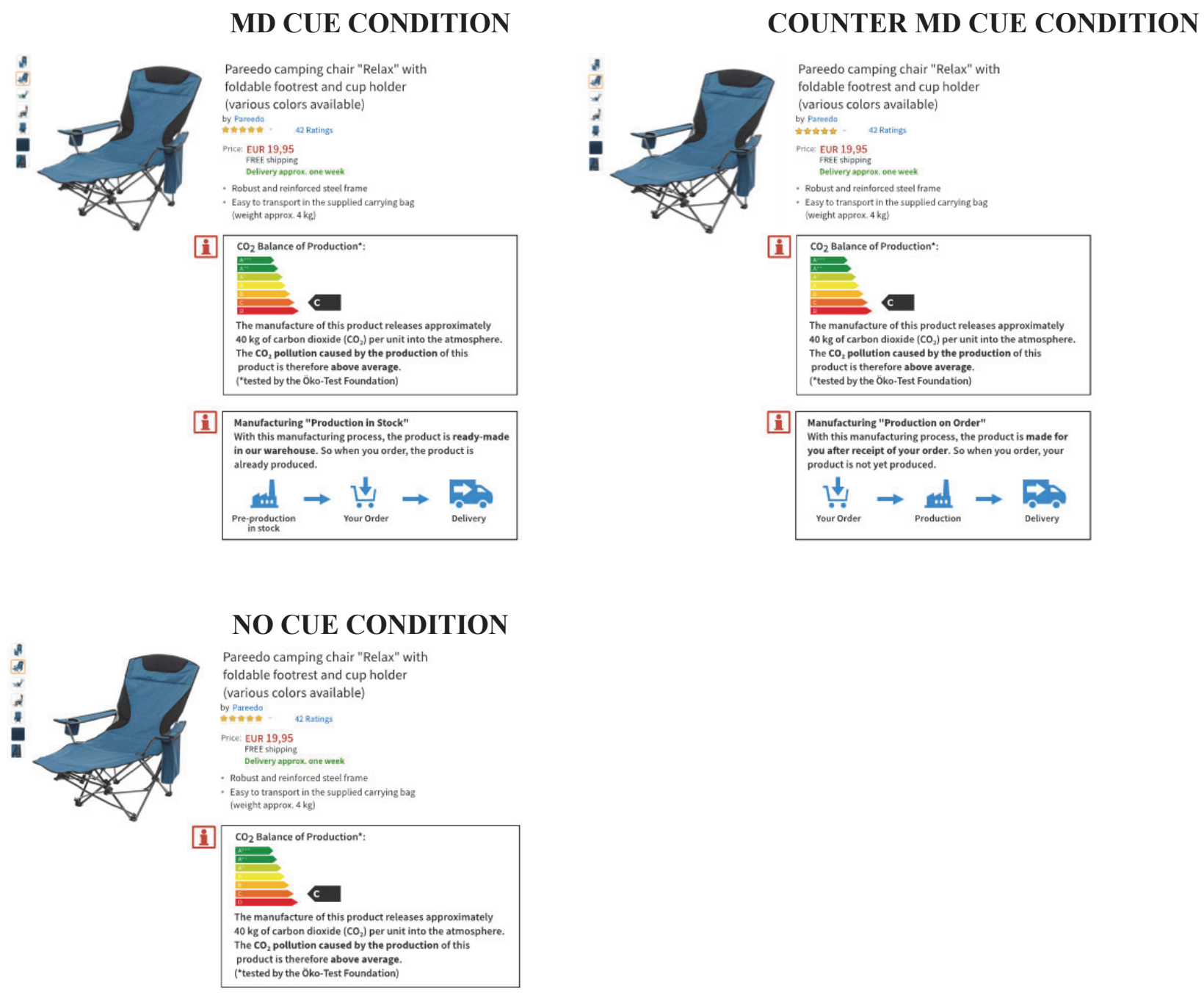

130 Journal of Organizational Psychology Vol. 20(1) 2020 


\section{B. MEASURES}

Perceived Self-Accountability for $\mathrm{CO}_{2}$ Impact* (Harland et al., 2007)

- I cannot be held accountable for the $\mathrm{CO}_{2}$ impact associated with the production of the product in case I opt for it.

- If I opt for this product, I am personally responsible for the $\mathrm{CO}_{2}$ impact associated with the production of this product.

Moral Feelings on Product Purchase* (Steg und Groot, 2010), (Harland et al. 2007)

- I would have a bad conscience if I purchase this product.

- I feel a strong personal obligation not to purchase this product.

- I would be proud if I would not purchase this product.

- I would feel guilty if I purchase the product.

- I would feel bad, if I purchase the product.

Purchase Intention* (Perugini und Bagozzi, 2001)

- I would purchase the offered product.

- It is likely that I use this product.

Word-of-Mouth-Intention* (Lindenmeier et al. 2012)

- I will recommend the offered product to my family.

- I will recommend my friends and acquaintances to purchase the offered product.

- I will recommend the offered product in social networks.

\section{Socio-ecological Product Performance**}

- Environmentally harmful vs. environmentally friendly

- Climate-damaging vs. climate-friendly

- Ecologically short-sighted vs. ecologically sustainable

\section{Perceived Product Desirability**}

- Unattractive vs. attractive

- Bad looking vs. good-looking

- Undesirable vs. desirable

*anchored from 1 "totally disagree" to 7 "totally agree", **1 left extreme, 7 right extreme 


\section{PROCESS Models}

PROCESS MODEL 3

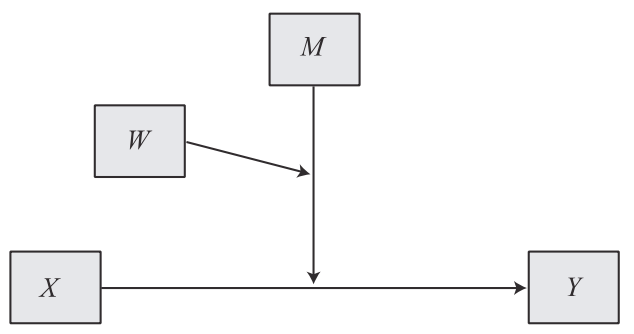

PROCESS CUSTOM MODEL

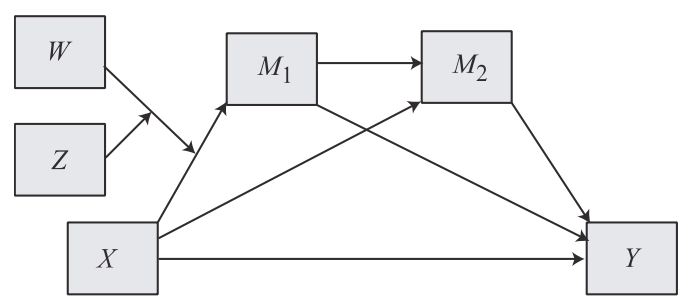

